\title{
Regeneration of Fibula Following Distal Fibulectomy for Ankle Arthrodesis Following the Use of Calcium Sulphate Granules: A Case Series and Review of the Literature
}

\author{
Poornanand Goru ${ }^{1}$, Syed Haque ${ }^{2}$, Tim Hirst ${ }^{3}$, Gopalkrishna G Verma ${ }^{4}$, Abubakar Mustafa ${ }^{5}$, Amer Shoaib ${ }^{6}$
}

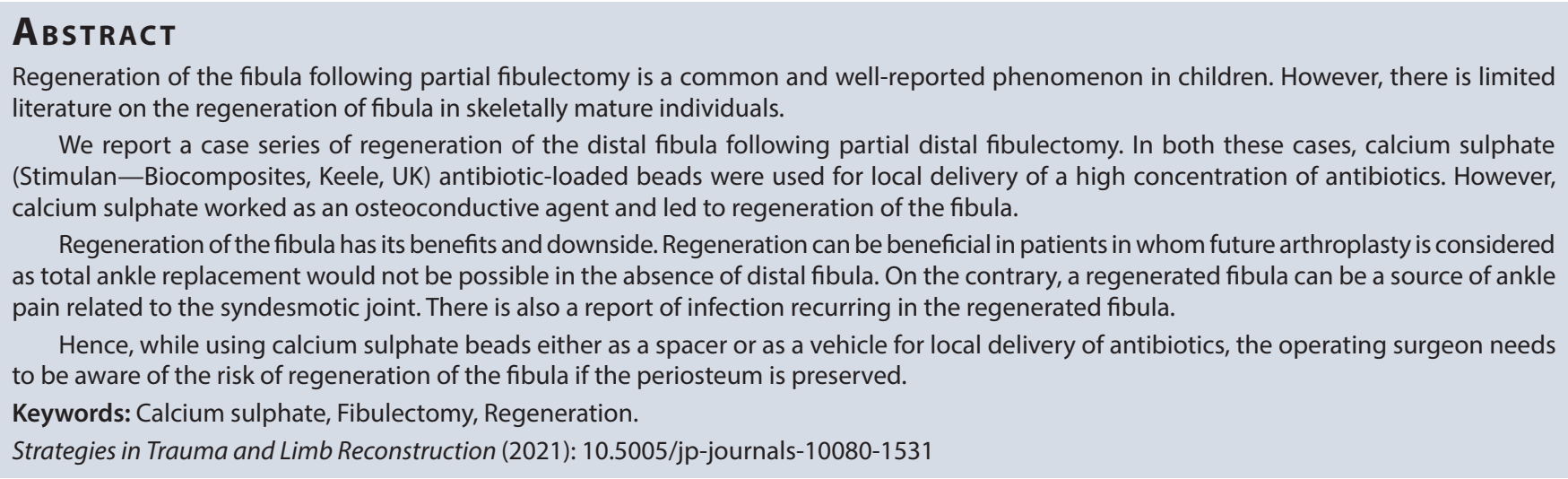

\section{INTRODUCTION}

Partial fibulectomy is a common procedure used for bone grafting as well as a surgical approach to the ankle joint for ankle fusion. ${ }^{1}$ There is evidence of regeneration of this osteotomised fibula following these procedures in paediatric patients especially if the periosteum preserving technique is used. ${ }^{2}$ Studies have found age to be the only predictor for the regeneration of the fibula with the cutoff age group being early adolescent patients in their teenage years. ${ }^{3}$ However, total regeneration of an osteotomised fibula is rarely reported in the literature in the adult population. ${ }^{4}$

We present a case series of fibular regeneration in adult patients following fibulectomy for ankle fusion in which calcium sulphate (Stimulan-Biocomposites, Keele, UK) was used as a vehicle for local antibiotic delivery as well as an osteoconductive agent.

These patients underwent an ankle fusion for infected post-traumatic arthritis following open reduction and internal fixation (ORIF) of an ankle fracture. A direct lateral approach was used and $6 \mathrm{~cm}$ of the distal fibula was resected. After the initial debridement of the infected wound tibiotalar, the articular surface was prepared meticulously using small osteotomes and a hammer. Relative stability for the fusion site was provided with the help of a ring external fixator. Freshly prepared calcium sulphate loaded with antibiotics was used both to deliver a high concentration of antibiotics locally as well as to work as an osteoconductive bone grafting agent to promote tibiotalar fusion. A routine postoperative blood test was done to monitor blood antibiotic levels from the cemented antibiotic beads. Postoperatively, patients were mobilised full weight-bearing. They were followed up in out-patient clinics where serial x-rays were performed. Apart from

\begin{abstract}
${ }^{1-6}$ Manchester University Hospitals NHS Trust, Manchester, United Kingdom

Corresponding Author: Poornanand Goru, Manchester University Hospitals NHS Trust, Manchester, United Kingdom, e-mail: drpoorna@ yahoo.com

How to cite this article: Goru P, Haque S, Hirst T, et al. Regeneration of Fibula Following Distal Fibulectomy for Ankle Arthrodesis Following the Use of Calcium Sulphate Granules: A Case Series and Review of the Literature. Strategies Trauma Limb Reconstr 2021;16(2):123-126.

Source of support: Nil

Conflict of interest: None
\end{abstract}

clinical and radiological evidence of tibiotalar fusion, these patients also showed regeneration of the fibula after 3 months of the index procedure.

\section{Case Descriptions}

\section{Case 1}

The first case was that of a 79-year-old female who sustained a trimalleolar left ankle fracture in Rome. She has no significant past medical history. She underwent primary fixation in Rome when a distal fibula locking plate was used to fix the lateral malleolus and the medial malleolus was fixed with two partially threaded cancellous screws. The posterior malleolus was not fixed.

Postoperatively, both the medial and lateral wounds broke down on return to the UK. Superficial wound swab showed a Staphylococcus aureus infection and an MRI scan confirmed

(-) Jaypee Brothers Medical Publishers. 2021 Open Access This article is distributed under the terms of the Creative Commons Attribution-Non Commercial-share alike license (https://creativecommons.org/licenses/by-nc-sa/4.0/) which permits unrestricted distribution, and non-commercial reproduction in any medium, provided you give appropriate credit to the original author(s) and the source, provide a link to the Creative Commons license, and indicate if changes were made. If you remix, transform, or build upon the material, you must distribute your contributions under the same license as original. The Creative Commons Public Domain Dedication waiver (http://creativecommons.org/publicdomain/zero/1.0/) applies to the data made available in this article, unless otherwise stated. 
osteomyelitis. She was started on a 6-week course of intravenous antibiotics as per the microbiologist's advice. Also, to control the infection, her metalwork was removed and a temporary spanning fixator was put in. Once the infection was under control clinically and inflammatory markers were returning to normal, she underwent a definitive procedure of a circular frame-assisted ankle and subtalar joint fusion. Beads of calcium sulphate loaded with $1 \mathrm{~g}$ vancomycin and $240 \mathrm{mg}$ gentamicin were placed into both the medial and lateral wounds (Fig. 1).

The frame was removed 4 months later once the fusion was confirmed both clinically and radiologically. Serial radiographs following the circular frame-assisted fusion on her follow-up initially demonstrated a shadow-like appearance of calcium sulphate beads which were later replaced by regenerating the fibula at the fibulectomy site (Fig. 2). The patient remains completely symptom-free from this regeneration of the fibula (Fig. 3).

\section{Case 2}

The second case was a 63-year-old female with a background of previous breast cancer, stroke, and anterior communicating

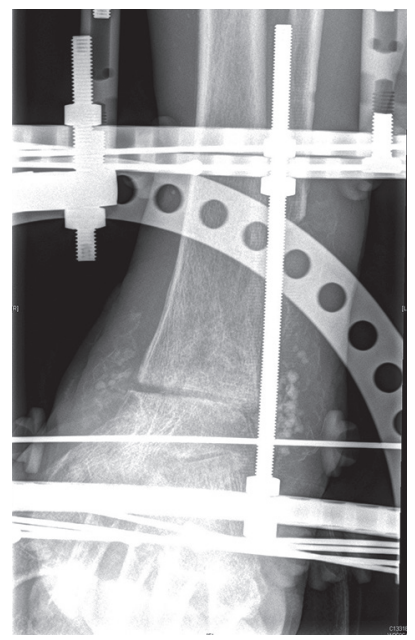

Fig. 1: X-ray after distal fibulectomy and the use of calcium sulphate beads

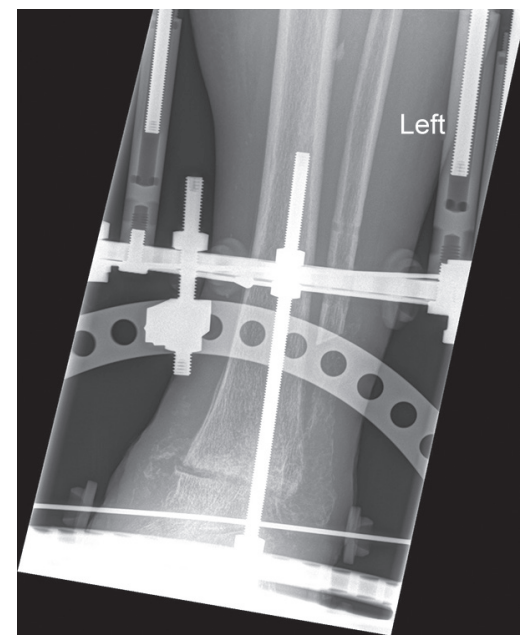

Fig. 2: X-ray of fibular regeneration 2 months after fibulectomy and use of calcium sulphate beads artery aneurysm. She sustained a right bimalleolar ankle fracture/ dislocation. This was initially reduced in the emergency department and she was put in a back slab. A week later, once the swelling settled, she underwent a primary ORIF with an interfragmentary screw and one-third tubular neutralisation plate for the lateral malleolus, two cancellous screws for the medial malleolus, and a positional screw through the lateral plate holding the syndesmosis.

Unfortunately, postoperatively, she developed a medial wound infection which subsequently broke down. She was referred to a limb reconstruction surgeon and underwent a two-staged circular frame-assisted ankle fusion 4 months after the initial procedure. Similar to the first case, $20 \mathrm{cc}$ of calcium sulphate beads mixed with $2 \mathrm{~g}$ vancomycin and $480 \mathrm{mg}$ gentamicin was inserted into the medial and lateral wounds (Fig. 4). Intraoperative microbiology samples grew Staphylococcus aureus and she was treated with oral antibiotics as per the microbiologist's advice.

The circular frame was removed 6 months later following both clinical and radiological evidence of union. Radiographs taken postoperatively initially showed the shadow of calcium sulphate in the distal fibulectomy site which gradually morphed into

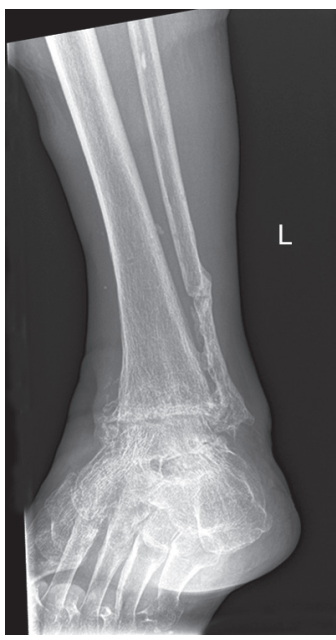

Fig. 3: X-ray of fibular regeneration 9 months after fibulectomy and use of calcium sulphate beads

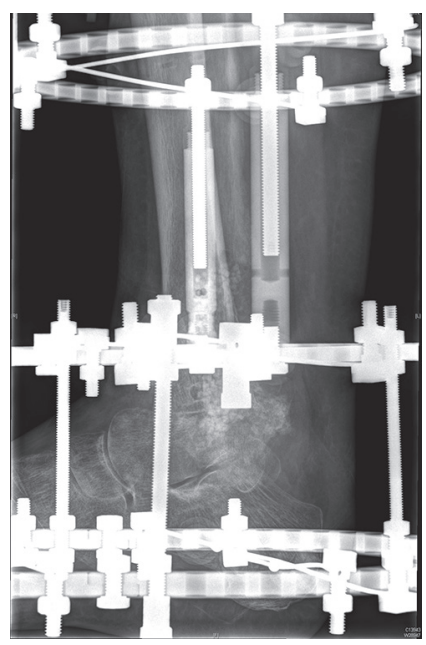

Fig. 4: X-ray after distal fibulectomy and the use of calcium sulphate beads 


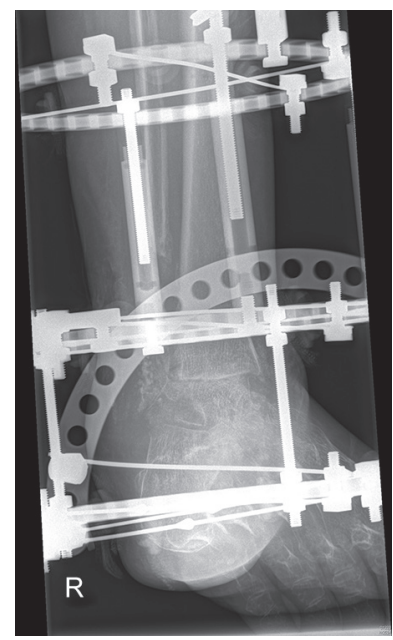

Fig. 5: X-ray of fibular regeneration 2 months after fibulectomy and use of calcium sulphate beads

the regenerated fibula (Fig. 5). This patient was also completely asymptomatic from the fibular regeneration (Fig. 6).

\section{Discussion}

The fibula is a common donor site for patients undergoing bone reconstruction. Its length, structure, and predictable vascular pedicle make it an ideal cortical bone graft. ${ }^{5,6}$ As with any surgical procedure, fibulectomy carries some morbidity and that has especially been documented in children. ${ }^{7}$

Fibular regeneration is common following osteotomy in paediatric patients. The regeneration rate for the paediatric age group varies from 50 to $100 \%{ }^{2,7}$ However, in the adult group, this is a rare occurrence and there is not enough literature available suggesting routine regeneration following fibulectomy. More importantly, the only predictor of regeneration of the fibula so far has been the age of the patient, 15 years being chosen as the cutoff age.

In our case series, we have used calcium sulphate as a vehicle for delivering a high concentration of local antibiotics as well as an osteoconductive agent. Calcium sulphate is a well-tolerated, biodegradable, osteoconductive bone graft substitute and is a good alternative to the autogenous bone graft. $^{8}$ Key features of this alloplastic material include its biocompatibility, rapid resorption rate, and unique ability to stimulate osteogenesis. ${ }^{9}$ Most of the calcium phosphate granules are reabsorbed radiologically within 6 months. ${ }^{10}$ When used as a spacer or osteoconductive agent, it has been found that up to $70-90 \%$ of the bone defect is replaced with the trabecular bone. ${ }^{11}$ The matrix is osteoconductive, which leads to new osseous growth. ${ }^{12}$ Self-limiting aseptic serous discharge lasting for 3-4 weeks is the most common complication associated with the use of calcium sulphate. ${ }^{13}$ This can be managed by a topical negative pressure dressing.

The significance of fibula preservation or regeneration in ankle arthrodesis is multiple - it increases the surface area for bony union, preserves the peroneal groove, prevents valgus drift in the cases of delayed union, and could facilitate future ankle arthroplasty. ${ }^{13}$ Although not essential, this fibular regeneration following distal fibulectomy can be potentially beneficial in transfibular osteotomies.

Conversely, regeneration of the fibula can result in morbidity. There are reports of recurrence of infection in the regenerated

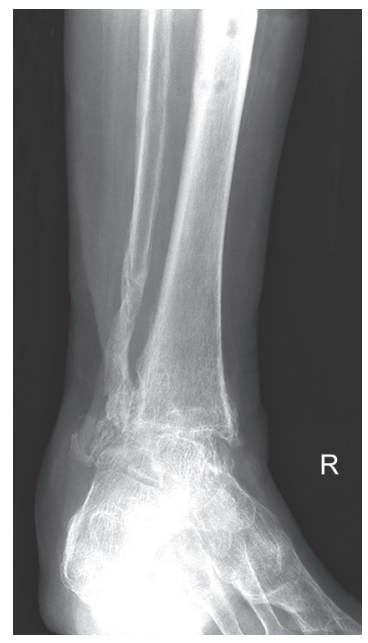

Fig. 6: X-ray of fibular regeneration 10 months after fibulectomy and use of calcium sulphate beads

fibula. ${ }^{14}$ Also, regeneration of the fibula may impinge the syndesmotic joint which can potentially be the source of pain.

The surgeon using calcium sulphate should anticipate regeneration of the fibula following fibulectomy. If this regeneration may be beneficial in the long term for the patient, then it is worth leaving the periosteum as this may further help in the regeneration of the fibula. On the contrary, if regeneration of the fibula can potentially cause significant morbidity including anterior ankle pain, then we strongly recommend debridement and possible excision of the periosteum to reduce the risk of regeneration of the fibula.

\section{Conclusion}

Our case series is the first of its kind in which regeneration of the fibula has taken place following the use of calcium sulphate.

The predominant role of calcium sulphate is osteoconduction, and while performing fibulectomy, if the periosteum is left behind, there is a high chance of its regeneration with the use of a stimulant.

Regeneration of the fibula has both potential benefits and disadvantages, and hence the surgeon should be aware of this effect of calcium sulphate while using it in fibulectomy in adults.

Further study may identify the exact incidence of fibular regeneration with the use of calcium sulphate when the periosteum is preserved.

\section{References}

1. Yang $L$, Xu HZ, Liang DZ, et al. Biomechanical analysis of the impact of fibular osteotomies at tibiotalar joint: a cadaveric study. Indian J Orthop 2012;46(5):520-524. DOI: 10.4103/0019-5413.101043. PMCID: PMC3491784.

2. Xin ZF, Kim KH, Jung ST. Regeneration of the fibula using a periosteumpreserving technique in children. Orthopedics 2009;32(11):820. DOI: 10.3928/01477447-20090922-14.

3. Bettin D, Böhm H, Clatworthy M, et al. Regeneration of the donor side after autogenous fibula transplantation in 53 patients: evaluation by dual x-ray absorptiometry. Acta Orthop Scand 2003;74(3):332-336. DOI: 10.1080/00016470310014274.

4. Edelman R, Barbacci D. Fibular regeneration. J Foot Surg 1992;31(4):368-371. PMID: 1401738.

5. Springfield D. Autograft reconstructions. Orthop Clin North Am 1996;27(3):483-492. PMID: 8649731. 
6. Weiland AJ, Moore JR, Daniel RK. Vascularized bone autografts. Clin Orthop 1983;174:87-95. PMID: 6339145.

7. González-Herranz P, del Río A, Burgos J, et al. Valgus deformity after fibular resection in children. J Pediatr Orthop 2003;23(1):55-59. PMID: 12499944.

8. Strocchi $R$, Orsini $G$, lezzi $G$, et al. Bone regeneration with calcium sulfate: evidence for increased angiogenesis in rabbits.J Oral Implantol 2002;28(6):273-278. DOI: 10.1563/1548-1336(2002)028<0273:BRWCS E>2.3.CO;2.

9. Yashavantha Kumar C, Nalini KB, Menon J, et al. Calcium sulfate as bone graft substitute in the treatment of osseous bone defects, a prospective study. J Clin Diagn Res 2013;7(12):2926-2928. DOI: 10.7860/ JCDR/2013/6404.3791.

10. Kelly CM, Wilkins RM, Gitelis $S$, et al. The use of a surgical grade calcium sulfate as a bone graft substitute: results of a multicenter trial. Clin Orthop Relat Res 2001;(382):42-50. DOI: 10.1097/00003086200101000-00008.

11. Gitelis S, Piasecki P, Turner T, et al. Use of a calcium sulfate-based bone graft substitute for benign bone lesions. Orthopedics 2001;24(2): 162-166. PMID: 11284599.

12. Borrelli J Jr, Prickett WD, Ricci WM. Treatment of nonunions and osseous defects with bone graft and calcium sulfate. Clin Orthop Relat Res 2003;(411):245-254. DOI: 10.1097/01. blo.0000069893.31220.6f.

13. Smith JT, Chiodo CP, Singh SK, et al. Open ankle arthrodesis with a fibular-sparing technique. Foot Ankle Int 2013;34(4):557-562. DOI: 10.1177/1071100713477617.

14. Al-Maiyah M, Hemmady MV, Shoaib A, et al. Recurrence of chronic osteomyelitis in a regenerated fibula after 65 years. Orthopedics 2007;30(5):403-404. DOI: 10.3928/01477447-20070501-12. 